\title{
Anticancer Potential of an Ethanol Extract of Saussurea Involucrata against Hepatic Cancer Cells in vitro
}

\author{
Munkhzaya Byambaragchaa ${ }^{1}$, Joseph dela $\mathrm{Cruz}^{2}$, Altantsetseg Kh${ }^{3}$, Seong-Gu \\ Hwang ${ }^{1 *}$
}

\begin{abstract}
Saussurea involucrata is a Mongolian medicinal plant well known for its effects in promoting blood circulation, and anti-inflammation and analgesic functions. Earlier studies reported that Saussurea involucrata has anticancer activity. The purpose of this study was to confirm the anticancer activity of an ethanol extract of Saussurea involucrata against hepatic cancer and elucidate its mechanisms of action. Hepatocellular carcinoma cells were tested in vitro for cytotoxicity, $\mathrm{AO} / \mathrm{EB}$ staining for apoptotic cells, apoptotic DNA fragmentation and cell cycle distribution in response to Saussurea involucrata extract (SIE). The mRNA expression of caspase-3,-9 and Cdk2 and protein expression of caspase-3,-9, PARP, XIAP, Cdk2 and p21 were analyzed through real time PCR and Western blotting. Treatment with SIE inhibited HepG2 cell proliferation dose- and time-dependently, but SIE only exerted a modest cytotoxic effect on a viability of Chang human liver cells. Cells exposed to SIE showed typical hallmarks of apoptotic cell death. Cell cycle analysis revealed that SIE caused G1-phase arrest in HepG2 cells. In conclusion, Saussurea involucrata ethanol extract has potential cytotoxic and apoptotic effects on human hepatocellular carcinoma cells. Its mechanism of action might be associated with the inhibition of DNA synthesis, cell cycle (G1) arrest and apoptosis induction through up-regulation of the protein expressions of caspase-3,-9 and p21, degradation of PARP and down-regulation of the protein expression of Cdk2 and XIAP.
\end{abstract}

Keywords: Saussurea involucrata - G1 phase arrest - apoptosis - HepG2 cells - growth inhibition

Asian Pac J Cancer Prev, 15 (18), 7527-7532

\section{Introduction}

\section{Introduction}

Liver cancer remains the sixth most frequently diagnosed cancer and the third leading cause of cancerrelated mortality globally (Chan and Yeo, 2012). It is estimated that 748,300 new liver cancer cases and 695,900 cancer deaths occurred in 2008. The world Health Organization (WHO) estimates that 84 million people would die of cancer between 2005 and 2015 . (Jemal et al., 2011). The current trend of cancer research is the investigation of medicines of plant origin because of their affordability and accessibility with minimal side effects. Treatment of hepatocellular carcinoma is clinically difficult, as HCC (hepatocellular carcinoma) expresses multidrug resistance genes and is highly associated with multi-gene, multi-factor, and multi-step processes (Huang et al., 1992; Padhya et al., 2013). HCC cells are characterized by high cellular levels of cyclin dependent kinases (Cdks). Up-regulation of Cdks results from the inactivation of $\mathrm{p} 16^{\text {Ink4 }}, \mathrm{p} 21^{\text {Wafl }}$ and $\mathrm{p} 27^{\mathrm{Kip} 1}, \mathrm{Cdk}$ inhibitory proteins, and abnormal activation of cyclins.

Saussurea involucrata KAR. et KIR., belongs to the
Asteraceae family, is a rare and beneficial traditional medicinal herb, grows in the mountains at heights of 4000-4300m in Mongolia and China. In recent years, the wild sources of S.involucrata have decreased dramatically due to the exhaustive collection for use in pharmaceutical preparations. In order to conserve the natural sources of S.involucrata, tissue culture is being developed, which might be used as a potential substitute for wild S.involucrata in the pharmaceutical industry (Guo et al., 2007; Desai et al., 2008). Cultured and wild S.involucrata showed the same phytochemical profile (Guo et al., 2007). The dried aerial parts of S.involucrata have long been used for the treatment of rheumatoid arthritis, impotence, irregular menses, cough with cold, stomachache, and altitude sickness (Li et al., 1989; Jia et al., 2005). Modern pharmacological studies showed that this plant has anti-inflammatory and analgesic (Jia et al., 2005), antimetastasis (Byambaragchaa et al., 2013) and anti cancer (Way et al., 2010) effects. Recent studies have shown that S.involucrata extract (SIE) has anti-cancer effect, however information on its potential mechanism remains limited. S.involucrata contains anti-cancer compounds such as rutin, hispidulin (Liu et al., 1985), apigenin (Li et al., 2006)

${ }^{1}$ Division of Animal Life and Environmental Science, Hankyong National University, Anseong, Republic of Korea, ${ }^{2}$ Department of Basic Veterinary Sciences, University of the Philippines Los Baños, College Laguna, Philippines, ${ }^{3}$ Department of Biotechnology and Breeding, Mongolian State University of Agriculture, Ulaanbaatar, Mongolia*For correspondence: sghwang@hknu.ac.kr 
and jaceosidin (Khan et al., 2012). Given the widespread traditional use and therapeutic potential of S.involucrata, further researches into the exact mechanisms of the actions exerted by SIE are warranted. Thus, the aim of this study was to investigate the potential mechanisms of cell death induced by SIE in HepG2 cells.

\section{Materials and Methods}

\section{Materials}

HepG2 (human hepatocarcinoma cells) cells were purchased from Korean Cell Line Bank in South Korea. Chang Liver normal cells were obtained from Konkuk University (South Korea). Fetal bovine serum (FBS), phosphate buffered saline (PBS), RPMI-1640 medium and Dulbecco's modified Eagle's medium (DMEM) were purchased from GIBCO BRL (Grand Island, NY, USA). Penicillin/streptomycin mix was purchased from Lonza (Walkersville, MD, USA). CCK-8 reagent was purchased from Dojindo (Kumamoto, Japan). Ethidium bromide was purchased from Bio basic Inc (Seoul, Korea) and acridine orange was purchased from Sigma (St. Louis, MO, USA). SYBR Green PCR Master Mix was purchased from Applied Biosystems. Antibodies were purchased from Santa Cruz Biotechnology (Santa Cruz, CA, USA), Abcam (Cambridge, United Kingdom) and Cell signaling Technology.

\section{Preparation of SIE}

Snow lotus (Saussurea involucrata) collected in Mongolia was used in this study. $10 \mathrm{~g}$ air-dried plants were kept in $500 \mathrm{ml} \mathrm{95 \%} \mathrm{ethanol} \mathrm{for} 48 \mathrm{~h}$ and then filtered. The extract was evaporated to dryness with a rotary vacuum evaporator and freeze-dried to give a powder. The stock solution of Saussurea involucrata extract (SIE) was prepared by dissolving snow lotus powder in culture medium $(10 \mathrm{mg} / \mathrm{mL})$ and the experimental concentrations were diluted in the basal medium.

\section{Cell culture}

Human hepatocarcinoma HepG2 cells were maintained in RPMI-1640 (Gibco) supplemented with $10 \%$ heatinactivated fetal bovine serum (FBS, Gibco), 100 units/ $\mathrm{mL}$ penicillin, and $100 \mu \mathrm{g} / \mathrm{mL}$ streptomycin under $5 \%$ $\mathrm{CO}_{2}$ in a humidified incubator at $37^{\circ} \mathrm{C}$.

\section{Cell viability analysis}

Cell viability was quantified by CCK-8 assay. Briefly, the cells were plated in 96-well culture plates at a density of $10^{5}$ cells $/ \mathrm{mL}$ and allowed to adhere at $37^{\circ} \mathrm{C}$ for $12 \mathrm{~h}$. Then cells were exposed to various doses of SIE. At various times after exposure, the media with various SIE concentrations were discarded; the cells were washed with PBS once. Then fresh media with CCK-8 reagent were added to each well. After 1 hour at $37^{\circ} \mathrm{C}$, the absorbance of OD450 was determined using an ELISA plate reader (Tecan, Switzerland). Morphological changes after exposure to SIE were observed by an inverted microscope.

\section{Nuclear staining}

Cells were exposed to $0-400 \mu \mathrm{g} / \mathrm{mL}$ of SIE for $48 \mathrm{~h}$ and stained nuclei with EB/AO dye mix containing $100 \mu \mathrm{g} / \mathrm{mL}$ acridine orange and $100 \mu \mathrm{g} / \mathrm{mL}$ ethidium bromide. Cells were viewed using confocal fluorescent microscope.

\section{Cell cycle analysis}

To determine cell cycle distribution analysis, $5 \times 10^{5}$ cells $/ \mathrm{mL}$ were plated in 6 well plates and treated with SIE $(0-400 \mu \mathrm{g} / \mathrm{mL})$ for $24 \mathrm{hr}$. After treatment, the cells were collected by trypsinization, fixed in $70 \%$ ethanol, washed in PBS, resuspended in $1 \mathrm{~mL}$ of PBS containing $1 \mathrm{mg} /$ $\mathrm{mL}$ RNase and $50 \mathrm{mg} / \mathrm{mL}$ PI, incubated in the dark for $30 \mathrm{~min}$ at room temperature, and analyzed by BD FACS Calibur flow cytometer. The data were analyzed using the CellQuestPro software.

\section{DNA fragmentation assay}

Cells $\left(5 \times 10^{5} / \mathrm{mL}\right)$ were treated with $0-400 \mu \mathrm{g} /$ $\mathrm{mL}$ of SIE for $24 \mathrm{~h}$, and then cells were collected by centrigufation. Pellets were lysed by DNA lysis buffer (10mM TrisHCl, 10mM EDTA, 0.5\% TritonX-100) and then centrifuged. The supernatant obtained was incubated overnight with proteinase $\mathrm{K}(0.1 \mathrm{mg} / \mathrm{mL})$ and then with RNAse $(0.2 \mathrm{mg} / \mathrm{mL})$ for $2 \mathrm{~h}$ at $37^{\circ} \mathrm{C}$. After extraction with phenol:chloroform:isoamylalcohol (25:24:1), the DNA was separated in $1.8 \%$ agarose gel and visualized by UV after staining with ethidium bromide.

\section{Quantitative real time PCR}

Total RNA was extracted using Trizol reagent according to the manufacturer's instructions (Invitrogen,MA, USA). Complementary DNA (cDNA) was obtained by following the protocol of THERMOScript RT-PCR System (Life Technologies). PCR was applied to cDNAs prepared from untreated and SIE treated samples. Quantitative PCR was performed using the Power SYBR Green PCR Master Mix from Applied Biosystems in a Bio-Rad C1000TM Thermal Cycler following the manufacturer's protocol. Amplification was carried out in a total volume of $20 \mathrm{ml}$ for 40 cycles of $15 \mathrm{~s}$ at $95^{\circ} \mathrm{C}, 20 \mathrm{~s}$ at $60^{\circ} \mathrm{C}$, and $30 \mathrm{~s}$ at $72^{\circ} \mathrm{C}$. Samples were run in triplicate and their relative expression was determined by normalizing expression of each target GAPDH. These were then compared with the normalized expression in control untreated sample to calculate a change value (\%). Primer sequences were as follows: human GAPDH: sense 5'-CGAGATCCCTCCAAAATCAA-3'; antisense 5'-AGGTCCACCACTGACACGTT-3', human caspase-3: sense 5'-TTTTTCAGAGGGGATCGTTG-3', antisense 5'-CGGTTAACCCGGGTAAGAAT-3', human caspase-9: sense 5'-AGGAACTCACAGCTCCATTAC-3', antisense 5'-CAGCATTAGCGACCCTAAGCA-3', human cdk2: sense 5'-GCCCTAATCTCACCCTCTCC-3'; antisense 5'-AAGGGTGGTGGAGGCTAACT-3'.

\section{Western blot}

The cells treated with $0-400 \mu \mathrm{g} / \mathrm{mL}$ SIE for 24 $\mathrm{h}$ were lysed in a protein extraction solution (Intron Biotechnology). The protein concentration was determined by the Bio-Rad protein assay (Bio-Rad Laboratories, Richmond, CA). For Western blotting, 30 micrograms of protein extraction was separated on $8-15 \%$ SDS- 
PAGE and electrotransferred to nitrocellulose membrane (Schleicher and Schuell, Germany). The membrane was blocked by incubation in 5\% skim milk in TBST buffer (20mM Tris- $\mathrm{HCl}, \mathrm{pH} 7.6,140 \mathrm{mM} \mathrm{NaCl}, 0.1 \%$ Tween 20) and then incubated with monoclonal anti-p21, anticdk2, anti-actin (Abcam), monoclonal anti-caspase-3, anti-caspase-9, anti-XIAP, and anti-PARP(Cell signaling technology) for 13-15h. The blot was washed with TBST buffer and incubated with horse radish peroxidase-labeled secondary antibody (Santa Cruz Biotechnology) for $2 \mathrm{~h}$. The membranes were then washed again, and detection was performed using the enhanced chemiluminescence system (Amersham).

\section{Statistical analysis}

All in vitro experiments were done in triplicate, and the experiments were repeated at least thrice. The intensities of the mRNA bands were normalized to the GAPDH bands and quantified by comparing with those of control cells. Data were expressed as means \pm standard deviations. The difference between control and SIE-treated cells was evaluated using Student's t test. P value less than 0.05 was considered statistically significant.

\section{Results}

\section{Inhibition of cell proliferation}

First, we tested the effects of SIE on the cell growth of hepatocarcinoma cell line, HepG2 and a normal hepatocyte, Chang normal cell. The cells were exposed to various doses of SIE for 0-72 $\mathrm{h}$ and cell viability was determined by CCK-8 assay. As shown in Figure $1 \mathrm{~A}$ and $B$, the survival curve showed that SIE had dose- and timedependent cytotoxic effects on HepG2 cells. In contrast, Chang normal liver cells were not markedly affected by the treatment with SIE $(400 \mu \mathrm{g} / \mathrm{mL})$ (Figure $1 \mathrm{C}, \mathrm{D})$. SIE reduced the proliferation of HepG 2 and Chang liver
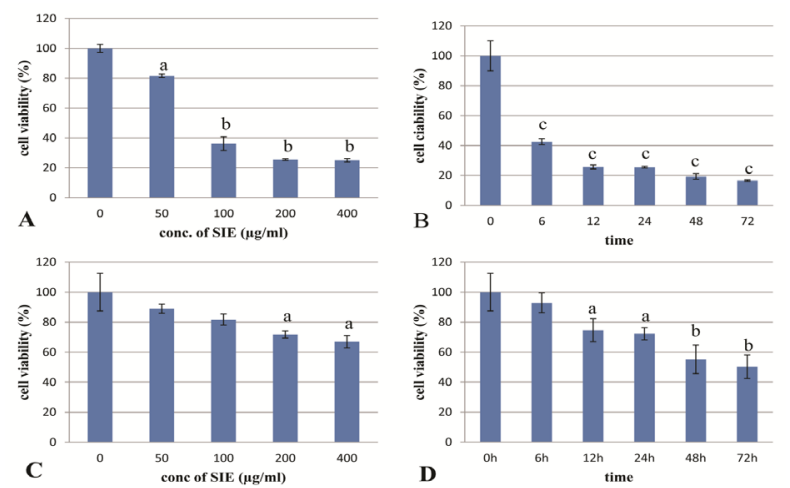

Figure 1. The Effects of SIE on the Growth Inhibition of HepG2 and Chang Liver Normal Cell Lines. A) Growth inhibition of increasing dose of SIE on HepG2 cells incubated for 24 hours; B) Growth inhibition of 200ug $/ \mathrm{mL} \mathrm{SIE}$ on HepG2 cells at different time intervals; C) Cell viability of Chang normal liver cells treated for 24 hours; D) Cell viability of Chang normal liver cells treated with $200 \mathrm{ug} / \mathrm{mL}$ SIE at different time intervals. Data represents the means $\pm S D(n=4)$, the (a) indicates a significant difference from the control $(\mathrm{p}<0.05)$; the (b) indicates significant difference from the control $(\mathrm{p}<0.01)$ and the (c) indicates significant difference from the control $(\mathrm{p}<0.001)$, Student's t test cells dose- and time- dependently with the $\mathrm{IC}_{50}$ value of $84.8 \mu \mathrm{g} / \mathrm{mL}$ and $616.99 \mu \mathrm{g} / \mathrm{mL}$, respectively. The inhibition of the cell proliferation could be the result of induction of apoptosis or cell cycle arrest. We hypothesized that SIE blocked hepatocarcinoma cell proliferation which caused the alterations of cell cycle progression and apoptosis.

\section{Changes in nuclei morphology after SIE treatment}

To determine whether the growth inhibitory activity of SIE was related to the induction of apoptosis, morphological assay of cell death was investigated using the AO/EB staining for fluorescence microscopy. After HepG2 cells were exposed to various concentrations of SIE for $24 \mathrm{~h}$, different morphological features were analyzed. Uniformly green live cells with normal morphology were seen in the control group (Figure 2A), whereas yellow early apoptotic cells with chromatin condensation and orange later apoptotic cells with fragmented chromatin and apoptotic bodies were seen when SIE was at the concentration of 200 and $400 \mu \mathrm{g} / \mathrm{mL}$ (Figure $2 \mathrm{~B}$ and C). The results suggested that SIE was able to induce marked apoptotic morphology in HepG2 cells .

\section{Effect of SIE on DNA fragmentation in HepG2 cells}

One of the mechanisms by which cell growth is suppressed is apoptotic cell death. Therefore, the effect of SIE on DNA fragmentation was examined in HepG2 cells. The DNA fragmentation was observed when cells were treated with $100,200,400 \mu \mathrm{g} / \mathrm{mL}$ of SIE for $24 \mathrm{~h}$. The profile for SIE induced apoptosis closely correlated with its growth suppressive effects. Thus, the growth suppression induced by SIE in HepG2 cells may be related to the induction of apoptosis.

\section{Cell cycle regulation}

The mechanism responsible for SIE-mediated cell proliferation inhibition, we analyzed the cell cycle
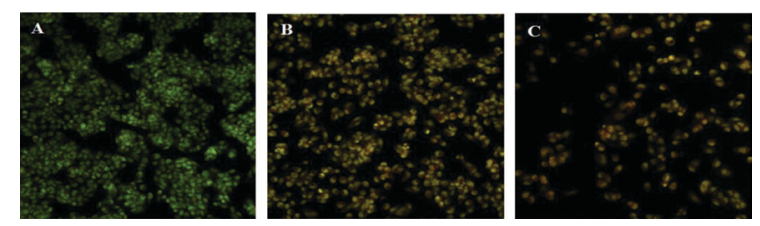

Figure 2. Effect of SIE on the induction of apoptotic morphological changes on HepG2 cells stained with AO/EB. A) Green live cells show normal morphology in control; B) yellow early apoptotic cells show chromatin condensation with $200 \mu \mathrm{g} / \mathrm{mL} \mathrm{SIE}$; C) $400 \mu \mathrm{g} / \mathrm{mL} \mathrm{SIE} \mathrm{treatment}$ showed orange later apoptotic cells, fragmented chromatin and apoptotic bodies $(\times 200)$

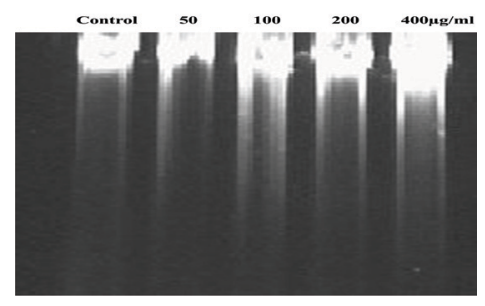

Figure 3. The Effect of SIE Treatment on DNA Fragmentation; Confirmed by Staining with Ethidium Bromide in 1.8\% Agarose Gel 
progression of HepG2 cells after treatment with SIE (various concentrations) for 24 hours (Figure 4) by flow cytometry. As shown in Figure 4, the results indicated that, compared with the control, $400 \mu \mathrm{g} / \mathrm{mL} \mathrm{SIE} \mathrm{increased}$ the population of SubG1 (apoptotic cells) phase from $3.74 \pm 0.04$ to $6.69 \pm 0.16 \%$ (Figure $4, \mathrm{p}<0.001$ ), $\mathrm{G} 1$ phase from $68.36 \pm 4.03$ to $83.66 \pm 3.28 \%$ (Figure $4, \mathrm{p}<0.01$ ) and decreased the population of $S$ phase from $7.34 \pm 0.29$ to $1.94 \pm 0.24$ (Figure $4, \mathrm{p}<0.001$ ) and $\mathrm{G} 2 / \mathrm{M}$ phase from $20.91 \pm 4.13$ to $7.81 \pm 0.6 \%$ (Figure $4, \mathrm{p}<0.01$ ). Thus, SIE induces cell cycle arrest and apoptosis in HepG2 cells.

\section{Cell cycle and apoptosis related gene expressions}

SIE induced cell cycle arrest and apoptosis cascade activation was determined further by the mRNA expressions of cell cycle and apoptosis related genes with Real Time PCR. The mRNA expressions of caspase-3 and caspase- 9 were up-regulated by $111.5 \%(\mathrm{p}<0.001)$
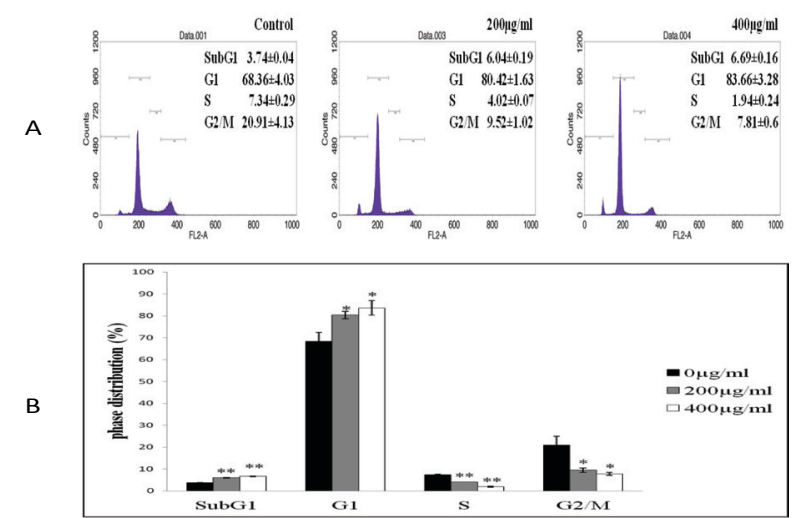

Figure 4. Cell Cycle Analysis of HepG2 Cells Treated with SIE. A) Cell cycle distribution and the percentage; B) of each phase determined and expressed as a percentage of total cell number $(* \mathrm{p}<0.01$ vs control, $* * \mathrm{p}<0.001$ versus respective control)
A

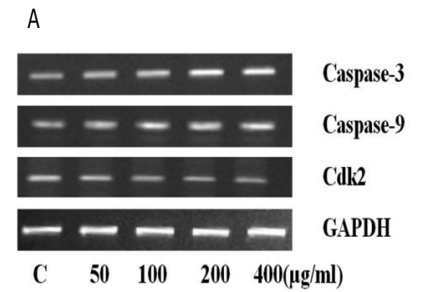

B

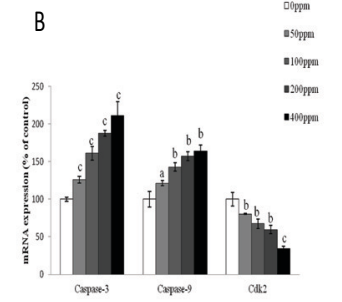

Figure 5. Effect of SIE on mRNA Expressions of cell Cycle and Apoptosis Related Genes of HepG2 Cells

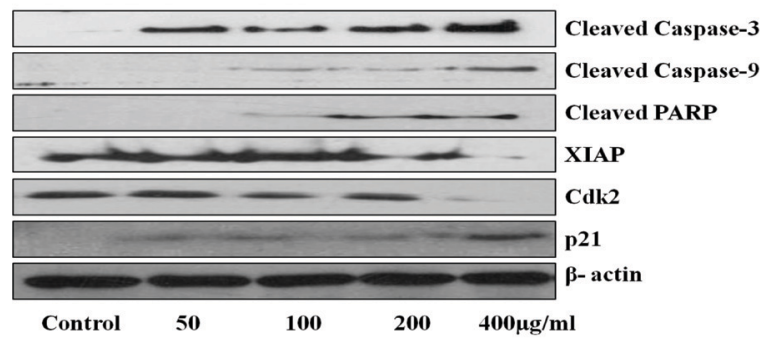

Figure 6. Effect of the SIE on Protein Expressions of Cell Cycle and Apoptosis Related Genes of HepG2 Cells and $64.28 \%(\mathrm{p}<0.01)$, respectively, while the mRNA expression of Cdk2 was down-regulated by $65.32 \%$ $(\mathrm{p}<0.001)$ after treatment of $400 \mu \mathrm{g} / \mathrm{mL}$ SIE for $12 \mathrm{~h}$ (Figure 5).

\section{Cell cycle and apoptosis related protein expressions}

To explore the potential signaling pathways underlying the SIE-induced apoptosis of cancer cells, cell cycle and apoptosis related protein expressions, cleaved caspase-3, cleaved caspase-9, cleaved PARP, XIAP, cdk2 and p21 were evaluated with western blotting. The expression levels of cleaved caspase-3, cleaved caspase-9, cleaved PARP and p 21 were increased in dose-dependent manner, and the expression levels of $\mathrm{Cdk} 2$ and XIAP were decreased in dose-dependent manner (Figure 6).

\section{Discussion}

Hepatocellular carcinoma is the most malignant cancer with a high incidence and mortality, for which current therapeutic approaches are still very limited, although chemotherapy is one of the important therapeutic modalities for HCC, the toxic effects are difficult to tolerate (Li et al., 2009; Lu et al., 2010; Roomi et al., 2010; Dai et al., 2011), so, there is an urgent need for development of better drugs which are more effective and simultaneously cause fewer side effects (Mukherjee et al., 2011; Shynu et al., 2011; Li-Weber, 2013). Natural therapies, such as the use of plant-derived products and traditional Chinese medicine (TCM) in cancer treatment, may reduce adverse side effects (Dai et al., 2011; Shynu et al., 2011; Wang et al., 2012), medicinal plants and natural products of plant origin are a rich source of cancer chemotherapy drugs, and exhibited low or almost no toxicity to normal tissues, hence, more attention is being paid to searching for new antitumor agents from natural products (Sigstedt at al., 2008; George et al., 2010).

Saussurea involucrata Kar et Kir belongs to the Asteraceae family, is a rare and beneficial traditional medicinal herb in Mongolia and China. The dried aerial parts of S.involucrata have long been used for the treatment of common diseases. Recent studies have shown that S.involucrata extract (SIE) has anti-cancer effect; however information on its potential mechanism remains limited. Therefore, further studies are needed to clarify the potential anticancer activity of Saussurea involucrata and its action mechanism.

In this study, SIE's anti-proliferative activities on hepatocarcinoma HepG2 cells and human Chang liver normal cells were elucidated. An extract demonstrated significant toxicity on $\mathrm{HepG} 2$ with $\mathrm{IC}_{50}$ value of at $84.8 \mu \mathrm{g} /$ $\mathrm{mL}$ and lower cytotoxicity on Chang liver normal cells with $\mathrm{IC}_{50}$ value of $616.99 \mu \mathrm{g} / \mathrm{mL}$.

Cell cycle arrest and apoptosis are two main ways for cell growth inhibition (Sun et al., 2011), natural products primarily target rapidly cycling tumor cells, inducing apoptosis of cancer cells as anticancer agents (Sreelatha et al., 2011).

After treatment with SIE, the characteristics of apoptotic cells, including the increase of EB/AO staining apoptotic cells (Figure 2) and evident DNA fragmentations 
(Figure 3), which are the important hallmarks of apoptosis. Cell cycle arrest of SIE treated cells was verified by cell cycle analysis. After treatment with SIE for $24 \mathrm{~h}$, cell numbers in SubG1 and G1 phases increased $(\mathrm{p}<0.01)$, and decreased in $S$ and $G 2 / M$ phase significantly $(p<0.01)$ in SIE treated cancer cells (Figure 4).

Generally, cell cycle arrest and apoptosis are connected; occurrence of cell cycle arrest leads to cell apoptosis, which need numerous signaling molecules and regulatory proteins. p21 plays an essential role in growth arrest after DNA damage, overexpression leads to G1 and G2 arrest and is highlighted as an important tumor suppressor (Erol, 2011; Masgras et al., 2012). It can bind and inhibit a broad range of cyclin/Cdk complexes, with preference for those containing Cdk2 (Zhang et al., 1993). Figure 6 shows that protein level of p21 is up-regulated by SIE in a dose-dependent manner in HepG 2 cells. This finding suggests that increased p21 is involved in cell cycle arrest by SIE.

Cdks regulate two biological processes essential for cancer cell survival; cell cycle progression and gene transcription (Nurse, 2009). Deregulation of the cell cycle, a process controlled by various cyclins, cyclindependent kinases (CDKs), CDK inhibitors, and certain tumor suppressor gene products, is known to be one of the critical events that drive cancer cells into uncontrolled proliferation (Dong et al., 2006). Cdk2 orchestrates the orderly progression of the eukaryotic cell cycle and plays a key role in the progression from late G1 to late G2 phase (Van den Heuvel and Harlow, 1993). It has been suggested that prolonged inhibition of Cdk2 within cells induces apoptosis and studies have speculated that Cdk2 inhibition decreases XIAP expression, releasing their ability to block cells from undergoing apoptosis (Dong et al., 2006). Inhibitor of apoptosis protein (IAP) is a family of proteins that regulate cell death; X-linked IAP (XIAP) is important member of this family in mammals. It inhibits caspases (caspase-3 and caspase-9) and block apoptosis (Salvesen and Duckett, 2002). The apoptotic effects of SIE in HepG2 cells appear to relate to changes in the cellular level of anti-apoptotic protein. Figure 6 shows that protein level of Cdk2 and XIAP are down-regulated by SIE in a dose-dependent manner in HepG2 cells. Therefore, our results support earlier studies suggesting that inhibition of $\mathrm{Cdk} 2$ leads to induction of apoptosis by down-regulating the cellular level of anti-apoptotic protein XIAP.

Human XIAP has been shown to be a direct inhibitor of caspase-3 and caspase-7 and to interfere with Bax/ cytochrome-c pathway by inhibiting caspase-9 (Deveraux et al., 1998; Takahashi et al., 1998). The transduction and execution of apoptotic signals requires the coordinated action of a cascade of caspases (aspartate-specific cysteine proteases). The caspases are present in cells as inactive procaspases, with the active tetramer being formed by removal of the prodomain and cleavage between the large and small subunits ( $\mathrm{Lu}$ et al., 2010). Caspase activity is responsible, either directly or indirectly, for cleavage of cellular proteins which are characteristically proteolysed during apoptosis. For example, caspase-3 and -9 can cleave poly-(ADP-ribose) polymerase (PARP). In our result, treatment with SIE caused an induction of caspase -3 and -9 activity and degradation of PARP, which precedes the onset of apoptosis. These results suggest that apoptosis induced by SIE involves a caspase-3-mediated mechanism.

Taken together, the potential anti-cancer activity of the SIE against hepatic cancer in vitro and its partial molecular mechanisms of activities were investigated in this experimental study. The results demonstrated that the Saussurea involucrata extract has strong anti-cancer activity against liver cancer without significant effect on normal cells. And the mechanism of its action might be associated with the inhibition of DNA synthesis, cell cycle arrest in G1 phase, apoptosis induction through caspase-3 mediated pathway. The Saussurea involucrata is a strong candidate for use an anti-cancer therapeutic agent for the treatment of hepatocellular carcinoma, and deserve to be investigated further.

\section{References}

Byambaragchaa M, De la Cruz JF, Yang SH, Hwang SG (2013). Anti-metastatic potential of ethanol extract of Saussurea involucrata against hepatic cancer in vitro. Asian Pac J Cancer Prev, 14, 5397-402.

Chan SL, Yeo W (2012). Targeted therapy of hepatocellular carcinoma: present and future. J Gastroenterol Hepatol, 27, 862-72.

Dai ZJ, Gao J, Li ZF, et al (2011). In vitro and in vivo antitumor activity of scutellaria barbate extract on murine liver cancer. Molecules, 16, 4389-400.

Desai AG, Qazi GN, Ganju RK, et al (2008). Medicinal plants and cancer chemoprevention. Current Drug Metabolism, 9, 581-91.

Deveraux QL, Roy N, Stennicke HR, et al (1998). IAPs block apoptotic events induced by caspase- 8 and cytochrome $\mathrm{c}$ by direct inhibition of distinct caspases. EMBO J, 17, 2215-23.

Dong F, Guo W, Zhang L, et al (2006). Downregulation of XIAP and induction of apoptosis by the synthetic Cdk inhibitor GW8510 in Non-small cell lung cacer cells. Cancer Biol Ther, 5, 165-70.

Erol A (2011). Genotoxic stress-mediated cell cycle activities for the decision of cellular fate. Cell Cycle, 10, 3239-48.

George S, Bhalerao SV, Lidstone EA, et al (2010). Cytotoxicity screening of Bangladeshi medicinal plant extracts on pancreatic cancer cells. MCC Complement Altern Med, 10, 52 .

Guo B, Gao M, Liu CZ (2007). In vitro propagation of an endangered medicinal plant Saussurea involucrata Kar. et Kir. Plant Cell Reports, 26, 261-5.

Huang CC, Wu MC, Xu GW, et al (1992). Overexpression of the MDR1 gene and P-glycoprotein in human hepatocellular carcinoma. J Natl Cancer Inst, 84, 262-4.

Jemal A, Bray F, Center MM, et al (2011). Global cancer statistics. CA Cancer J Clini, 61, 69-90.

Jia JM, Wu CF, Liu W, et al (2005). Antiinflammatory and analgesic activities of the tissue culture of Saussurea involucrata. Biol Pharm Bull, 28, 1612-4.

Khan M, Yu B, Rasul A, et al (2012). Jaceosidin induces apoptosis in U87 glioblastoma cells through $\mathrm{G} 2 / \mathrm{M}$ phase arrest. eCAM: Evid Based Complement Altern Med, 2012, 703034.

Li GH, Fa L, Zhao RC (1989). Studies on pharmacological actions of Saussurea involucrata Kar. et Kir. Acta Pharm Sinic, 15, 368-9.

Li FX, Jin ZP, Zhao DX, et al (2006). Overexpression of the Saussurea medusa chalcone isomerase gene in S. involucrata 
Munkhzaya Byambaragchaa et al

hairy root cultures enhances their biosynthesis of apigenin. Phytochemistry, 67, 553-60.

Li ZF, Wang ZD, Ji YY, et al (2009). Induction of apoptosis and cell cycle arrest in human HCC MHCC97H cells with chrysanthemum indicum extract. World J Gastroenterol, 15, 4538-46.

Li-Weber M (2013). Targeting apoptosis pathways in cancer by Chinese medicine. Cancer Letters, 332, 304-12.

Liu L, Xiao X, Zhang L (1985). Effect of the flavonoids from Saussurea involucrata on DNA synthesis of cancer cells. $J$ Lanzhou University Nat Sci, 21, 80-3.

Lu CX, Nan KJ, Nie YL, et al (2010). Delisheng, a Chinese medicinal compound, exerts anti-proliferative and proapoptotic effects on HepG2 cells through extrinsic and intrinsic pathways. Mol Biol Rep, 37, 3407-12.

Masgras I, Carrera S, de Verdier PJ, et al (2012). Reactive oxygen species and mitochondrial sensitivity to oxidative stress determine induction of cancer cell death by $\mathrm{p} 21 . J$ Biol Chem, 287, 9845-54.

Mukherjee AK, Basu S, Sarkar N, et al (2011). Advances in cancer therapy with plant based natural products. Curr Med Chem, 8, 1467-86.

Nurse P (2000). A long twentieth century of the cell cycle and beyond. Cell, 100, 71-8.

Padhya KT, Marrero JA, Singal AG (2013). Recent advances in the treatment of hepatocellular carcinoma. Curr Opin Gastroenterol, 29, 285-92.

Roomi MW, Roomi NW, Kalinovsky T, et al (2010). In vivo and In vitro effect of a nutrient mixture on human hepatocarcinoma cell line SK-HEP-1. Exp Oncol, 32, 84-91.

Salvesen GS, Duckett CS (2002). IAP proteins: blocking the road to death's door. Nature Rev Mol Cell Biol, 3, 401-10.

Shynu M, Gupta PK, Saini M (2011). Antineoplastic potential of medicinal plants. Recent Pat Biotechnol, 5, 85-94.

Sigstedt SC, Hooten CJ, Callewaert MC, et al (2008). Evaluation of aqueous extracts of taraxacum officinale on growth and invasion of breast and prostate cancer cells. Int J Oncol, 32, 1085-090.

Sreelatha S, Jeyachitra A, Padma PR (2011). Antiproliferation and induction of apoptosis by Moringa oleifera leaf extract on human cancer cells. Food Chem Toxicol, 49, 1270-5.

Sun B, Geng S, Huang X, et al (2011). Coleusin factor exerts cytotoxic activity by inducing G0/G1 cell cycle arrest and apoptosis in human gastric cancer BGC-823 cells. Cancer Lett, 301, 95-105.

Takahashi R, Deveraux Q, Tamm I, et al (1998). A single BIR domain of XIAP sufficient for inhibiting caspases. J Biol Chem, 273, 7787-90.

Van den Heuvel S, Harlow E (1993). Distinct roles for cyclindependent kinases in cell cycle control. Science, 262, 2050-4.

Wang S, Hu Y, Tan W, et al (2012). Compatibility art of traditional Chinese medicine: from the perspective of herb pairs. J Ethnopharmacol, 143, 412-23.

Way TD, Lee JC, Kuo DH, et al (2010). Inhibition of epidermal growth factor receptor signaling by Saussurea involucrata, a rare traditional Chinese medicinal herb, in human hormoneresistant prostate cancer PC-3 Cells. J Agricultural Food Chem, 58, 3356-65.

Zhang H, Xiong Y, Beach D (1993). Proliferating cell nuclear antigen and $\mathrm{p} 21$ are components of multiple cell cycle kinase complexes. Mol Biol Cell, 4, 89-906. 